\title{
EVALUATING RISK FACTORS FOR MULTI DRUG RESISTANCE POST LIVING DONOR LIVER TRANSPLANTATION.
}

\author{
Sarah Osman ${ }^{1}$, Abd El-hamid EI Shamy ${ }^{2}$, Hany Dabbous ${ }^{3}$, Iman Fawzy $^{3}$, Mahmoud El- \\ Meteini $^{4}$
}

1- Clinical Pharmacist at Clinical Pharmacy Unit of Ain Shams University Specialized hospital.

2- Pharmaceutics and Industrial Pharmacy Faculty of Pharmacy Ain Shams University

3- Tropical Medicine Department, College of Medicine, Ain Shams University

4- Liver Surgery \& Liver Transplantation Director of Organ Transplantation Unit Ain Shams

University

\section{Hazem_ch@hotmail.com}

\begin{abstract}
Living donor liver transplantation (LDLT) has been used for end stage liver disease (ESLD) since 1989. LDLT has basically resolved the problem of donor organ shortages. However, early complications postoperatively and long term life quality are issues that still need to be resolved. Bacterial infections remain by far the most frequently occurring infectious complication in liver transplant recipients. The main aim of the study is to point out the main risk factor for antimicrobial resistance post LDLT. In the current study, a total of 42 recipients, 7 females and 35 males who underwent LDLT at Ain Shams Center For Organ Transplantation "ASCOT". All recipients were screened for the presence of risk factors that affect patients' susceptibility to infection and hence to antimicrobial resistance either preoperative or intra operative or post operative. The observational study was done prospectively. Results obtained in the present study revealed the age of all recipients ranged from 42 to 63 years old. (mean value of $53.5 \pm 6.4$ years). Prolonged Operative time $(\mathrm{P}=0.016)$, multiple radiological interventions $(\mathrm{P}=0.040)$, and multiple antibiotic changes post operatively $(\mathrm{P}=0.38) \quad$ were the independent risk factors for developing infection after liver transplantation in our center. The present study confirms that infection is a frequent and major cause of morbidity and mortality after liver transplantation. Current findings suggested postoperative bacterial infections were associated with pre-, intra- and post-operative factors, so careful monitoring and management is very important to improve patients' outcome.
\end{abstract}

\section{INTRODUCTION}

Liver Transplantation has become the gold standard in the treatment of advanced chronic liver disease and fulminant hepatic failure. LDLT has basically resolved the problem of donor organ shortages (Sang et al., 2011). Infection after liver transplantation, especially bacterial infection is the main early complication after the operation. It is reported that the rate of bacterial infection is often more than $60 \%-80 \%$ and often at least no less than 2 organs or positions that are infected by bacteria (Soong $\boldsymbol{e t}$ al., 2012). Bacteremia has been reported to be the main cause of mortality in liver transplant recipients. The mortality in bacteremic liver transplant recipients has been found to range between $24 \%$ and $36 \%$ (Joy $\boldsymbol{e t}$ al., 2012). In addition, the release of cytokines during the infection may have other indirect and negative effects, including allograft injury,opportunistic super infection and malignancy. (Kim et al., 2013). 
After solid organ transplantation, there are 3 time periods when specific infections are likely to occur . During the first month, infections are typically of nosocomial origin. Depending on the circumstances of each case, surgical technique- related infection is located fundamentally in the abdomen, liver and biliary tract, and includes superficial and deep infection of the surgical bed (surgical wound, intra-hepatic and extra-hepatic abscesses, peritonitis and cholangitis). In the intermediate period, from the second to the sixth months, the higher immunosuppression period, bacterial infections (opportunistic bacteria) are less common than viral infections (especially cytomegalovirus, recurrence of HCV, Epstein-Barr and adeno-viruses). After the sixth month, with the transplanted organ functioning normally and minimum immunosuppressive doses, the frequency of bacterial infections is reduced to figures similar to those of the general population and the causes are pathogenic bacteria of the community (Lupei et al., 2010).

\section{MATERIALS AND METHODS}

In the current study, a total of 42 recipients, from ASCOT were recruited pretransplant and followed up during both intra and post transplant periods for a maximum of three months post transplant according to the occurrence of post transplant bacterial infection with resistant strains, participants were categorized into:

Group I: included 20 recipients without post operative bacterial infection.

GroupII: case group included 22 recipients with post operative bacterial infections with resistant bacterial strains.

Multiple-antibiotic resistance was defined according to similarly conducted studies as enterococci resistant to vancomycin; $S$ aureus resistant to methicillin; Enterobacteriaceae resistant to at least two of the following antibiotics: piperacillin, ciprofloxacin, thirdgeneration cephalosporins, or gentamicin and $P$ aeruginosa resistant to at least two of the following antibiotics: piperacillin, ciprofloxacin, ceftazidime, imipenem, or gentamicin. Extended-spectrum penicillins were defined as piperacillin, and piperacillin-tazobactam (Augustin et al., 2010).

All recipients was screened for the presence of any risk factor that affects patients' susceptibility to infection and hence to antimicrobial resistance either preoperative or intra operative or post operative.

Routine cultures were withdrawn on first post operative day in the ICU and once the patient is transferred to the ward. Also, in case patient gets feverish, pan cultures (Urine, sputum, blood, bile, abdominal drain) would be taken.

\section{Statistical analysis of data}

Tabulated collected data was introduced to PC using SPSS 15.01 for windows. Descriptive statistics was expressed as mean, $\pm \mathrm{SD}$, range, and median ( non parametric numerical data) and percentage for non numerical data. For Analytical statistics both student t- test and Mann Whitney test were used to assess the statistical significance of the difference between quantitative variable while chi-square test and fischer exact test were used to assess the statistical difference of qualitative variables. 


\section{RESULTS}

Patient demographic as well as hepatic disease characteristics were described in table -1-. The age of all recipients ranged from 42 to 63 years old. Most of the patients were HCV infected with mean Model of end stage liver disease (MELD) score of 15.5 \pm 2.0 .

Table-1- Comparison between cases and controls as regard demographic and characteristics of chronic liver disease

\begin{tabular}{|c|c|c|c|c|c|}
\hline \multirow{3}{*}{\multicolumn{2}{|c|}{ variable }} & \multicolumn{4}{|c|}{ Group } \\
\hline & & \multicolumn{2}{|l|}{ cases } & \multicolumn{2}{|c|}{ controls } \\
\hline & & Mean & $\pm \mathrm{SD}$ & Mean & $\pm \mathrm{SD}$ \\
\hline \multicolumn{2}{|l|}{ Age } & 53.5 & 6.4 & 54.2 & 4.5 \\
\hline \multicolumn{2}{|c|}{ BMI (body mass index) } & 28.9 & 4.5 & 27.7 & 3.8 \\
\hline \multicolumn{2}{|c|}{ MELD score } & 17.5 & 4.1 & 15.5 & 2.0 \\
\hline \multirow[t]{2}{*}{ Sex } & Male (n \%) & 19 & $86.4 \%$ & 16 & $80.0 \%$ \\
\hline & Female (n \%) & 3 & $13.6 \%$ & 4 & $20.0 \%$ \\
\hline \multirow{3}{*}{$\begin{array}{l}\text { Child pugh } \\
\text { score class }\end{array}$} & Child A & 0 & $.0 \%$ & 0 & $.0 \%$ \\
\hline & Child B & 6 & $27.3 \%$ & 6 & $30.0 \%$ \\
\hline & Child C & 16 & $72.7 \%$ & 14 & $70.0 \%$ \\
\hline \multirow[t]{2}{*}{ Diagnosis } & $\mathrm{HCV}(\mathrm{n} \%)$ & 8 & $36.4 \%$ & 7 & $35.0 \%$ \\
\hline & HCC (n \%) & 14 & $63.6 \%$ & 13 & $65.0 \%$ \\
\hline
\end{tabular}

Pre transplant data findings showed that existence of co-morbidity, Spontaneous bacterial peritonitis, prior hospital admission, abdominal paracentesis, radiological intervention and portal vein thrombosis revealed significant difference between case and control groups. However Age, sex, BMI, alcohol intake, MELD score, Child Pugh score, aetiology of hepatopathy, pleural paracentesis and prior abdominal surgery showed no significant differencebetween two groups .

Similarly, Intra-operative data findings showed that operative time, blood loss, blood product intake as packed $\mathrm{RBCs}$ and fresh frozen plasma, need for inotropes and hemodynamically instability revealed significant difference between the two groups. However graft recipient weight ratio, use of venous graft, type of biliary anastomosis, complication events and additional procedures showed no significant difference between the two groups.

Additionally, Post transplant data findings showed significant difference between the two groups as regard to extubation time, change of prophylactic antibiotic, biliary complication, incidence of vascular insult, any radiological intervention, reoperation, episodes of abnormal high immunosuppression level, duration of urinary catheter, duration of central line, ICU stay and hospital stay. However acute rejection episodes and acute rejection with high dose steroids showed no significant difference between the two groups.

After adjustment to risk factors using multivariate rgression, operative time, radiological interventions, and antibiotic change post operatively were proved to be the independent risk factors for developing infection after LDLT in ASCOT (Table 2) 
Table -2- Multivariate regression analysis of independent risk factors for developing resistant infection after liver transplantation

\begin{tabular}{|l|l|l|l|}
\hline variable & Odds ratio & P-value & Significance \\
\hline Operative time & 3.323 & .016 & $\mathrm{~S}$ \\
\hline Radiological intervention & 26.745 & .040 & $\mathrm{~S}$ \\
\hline Antibiotic change & 6.362 & .038 & $\mathrm{~S}$ \\
\hline
\end{tabular}

\section{DISCUSSION}

Postoperative infections have been identified to negatively impact outcome after liver transplantation. It is the major cause of morbidity and the leading cause of mortality (Kim $e t$ al., 2013).

Bacterial infections remain by far the most frequently occurring infectious complication in liver transplant recipients (Lupei et al., 2010).

Despite improvements in surgical technique, prolonged graft function and progress in therapeutic options, the rate of major infectious complication remains high (Joy et al., 2012).

Liver transplant recipients are generally immunocompromised. Furthermore, the pretransplant conditions between patients are considerably variable (Dipiro et al., 2013).

Duration of operation in this current study proved to be crucial risk factor for developing post LDLT bacterial infection, as longer operative time increases the risk of post operative infection. This data was in line with Pungpapong et al. (2006) and Asensio et al. (2008) who both confirmed that transplants were complicated by infection more frequently in patients who had longer duration of surgery at the time of liver transplantation.

In the current study hemodynamically instability and performing additional procedure at the same surgical session lengthen the operative time and hence increase the incidence of post operative infection. This was evidenced in the Present study by infectious episodes due to gram negative bacterial strain predominantly occurred in patients with acute severe exacerbation of chronic hepatitis who were critically ill and apt to have higher complexity with surgical complexity such as large intra operative blood loss and longer operative time which were associated with liver transplant multiple drug resistance (MDR) strains. These results are in line with Shoo-hua et al. (2010) a similar conducted study.

Also, frequent empirical antibiotic use and its long duration post transplant could enhance the likelihood of emergence of extensive antimicrobial resistant pathogen. Hashimoto et al. (2010) and Shi et al. (2009) confirmed this data and added that in their study, patient received long courses of multiple antimicrobials resulting in broad coverage and hence acquisition of MDR bacterial strain may also be due to cross resistance among antibiotics.

Excessive use of antibiotics can increase the risk of infection in patients postoperatively while primary infection was cured clinically by broad spectrum antibiotics, the use of antibiotics also increase the chance of gram negative infections (Kim et al., 2013).

In the current study, the pathogenic bacteria were gram negative bacteria with high level drug resistance. The emergence of these pathogens was due to extended use of broad spectrum antibiotics in group two particularly third generation cephalosporins. Therefore, the preoperative use of antibiotics should be strictly controlled especially the application of 
broad spectrum antibiotics for effective reduction of the risk of gram negative infections in patient following liver transplantation surgery. These obtained results were in agreement with Soong et al. (2012). However Hashimoto et al. (2008) reported that the extensive use of antimicrobials measured by the presence of pre antibiotics used during the month before liver transplant did not correlate with the acquisition of infection after transplantation which was in accordance with our results.

\section{CONCLUSION}

The present study confirms that infection is a frequent and major cause of morbidity and mortality after liver transplantation.

Current findings suggested postoperative bacterial infections to be associated with pre-, intra- and post-operative factors. Operative time, change of antimicrobial therapy and radiological intervention were the most important risk factor for antimicrobial resistance.

Evaluating the active contribution of these factors to the occurrence of post liver transplantation infection eventually should lead to a better clinical practice avoiding such burden on transplant patient via modulating preventable risk factors.

\section{REFERENCE}

Asensio A., Ramos A., et al. (2008): "Effect of Antibiotic prophylaxis on the risk of surgical site infection in orthotopic Liver transplant". Liver Transplantation Journal. 14(6):799-805.

Augustin P, Kermarrec N, et al. (2010): Risk factors for multidrug resistant bacteria and optimization of empirical antibiotic therapy in postoperative peritonitis. Critical Care;2010 14(20):1-8.

Dipiro J, Talbert $\boldsymbol{R}$ et al, (2013): "Pharmacotherapy: A pathophysiologic approach". Section 11 : Immunologic disorder. McGraw-Hill Medical 8th edition.

Hashimoto M., Sugawara Y., et al. (2008): "A question of methicillin-resistant staphylococcus aureus after living donor Liver transplantation: a retrospective cohort study". BMC Infect Dis. 8:155-160.

Hua S. S., Shen K. H., et al. (2010): "Coagulase-negative staplylo coccus and enterococcus as pre-dominant pathogen in Liver transplant recipients with Gram positive coccal bacteremia. Chinese Medical Journal. 123(15):1983-8.

Joy Varghese, Narasimhan Gomathy, et al. (2012): Perioperative Bacterial Infections in Deceased Donor and Living Donor Liver Transplant Recipients, Journal of Clinical and Experimental Hepatology.

Kim S.I., Y.J. Kim, et al. (2013): Strategies to Reduce Infectious Complication Using Epidemiologic Data Analysis in Liver Transplant Recipients, Transplantation Proceedings, 45(8):3061-4

Lupei M, I., Henry J. Mann, et al. (2010): Inadequate Antibiotic Therapy in Solid Organ Transplant Recipients Is Associated with a Higher Mortality Rate, Surgical Infections, 11(1):33-9

Pungpapong S, Alvarez S, et al. (2006): "Peritoritis after liver transplantation; Incidence, Risk Factors, Microbiology Profiles, and outcomes". Liver Transplantation Journal. 12(8):1244-52 
Sang-Oh Lee, Seung H. Kang, et al., (2011): Spectrum of early-onset and late-onset bacteremias after liver transplantation: Implications for management, Liver Transplantation, 17(6):733-41

Shi SH, Kong HS et al. (2009): "Multidrug resistant gram-negative bacilli as predominant bacteremic pathogens in Liver transplant recipients". Transplant infection Disease. 11(5):405-12

Soong R. S., K.-M. Chan, H.-S. Chou, T.-J. Wu, C.-F. Lee, T.-H. Wu, W.-C. Lee, (2012): The Risk Factors for Early Infection in Adult Living Donor Liver Transplantation Recipients, Transplantation Proceedings, 44(3):784-6

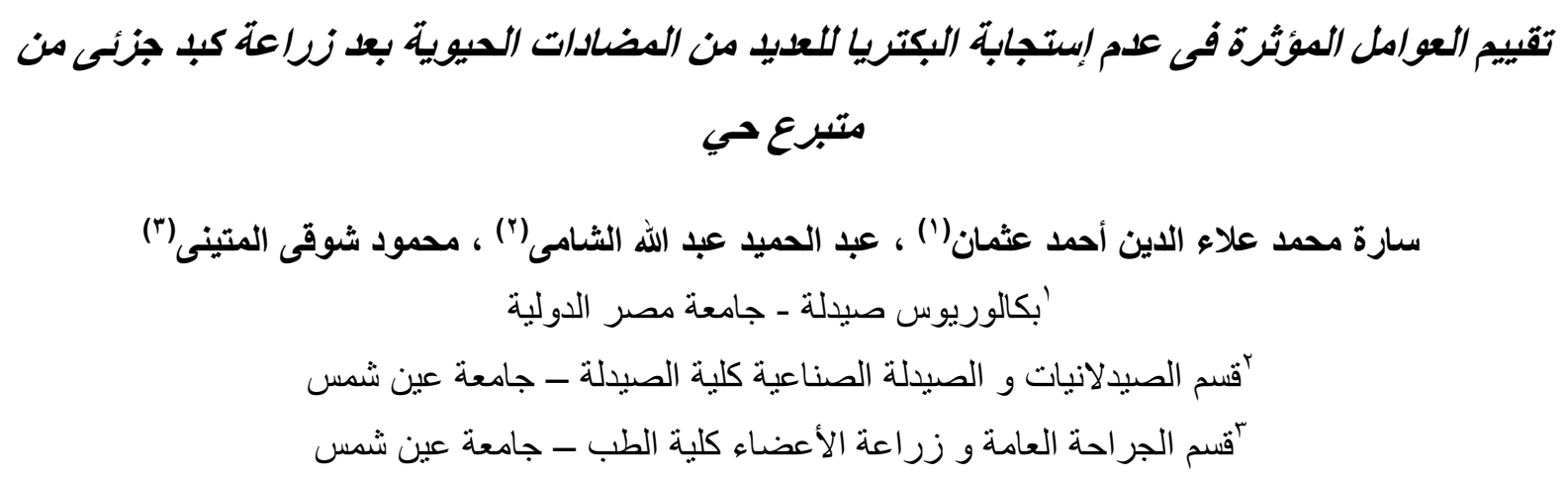

تجرى زر اعة كبد جزئى من متبرع حى منذ عام 919 أكحل للفشل الكبدى ، وتعتبر هذه الطريقة حلاً بديلاً لتدارك نقص التبرع بالكبد الكامل . ولكن لاز ال هناك بعض المشاكل التى تحدث على المدى القريب و المدى البعيد التى تتطلب حل جزرى .

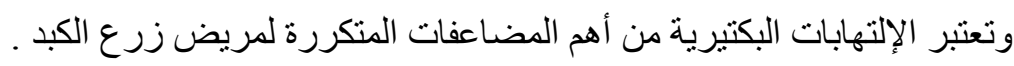

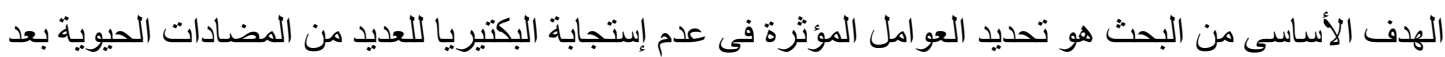
زر اعة الكبد.

تحتوى هذه الدارسة على عدد إثثين وأربعين مريض تم إجر اء زر اعة كبد جزئى لهم من متبر ع حى فى مستشفى عين شمس التخصصى .



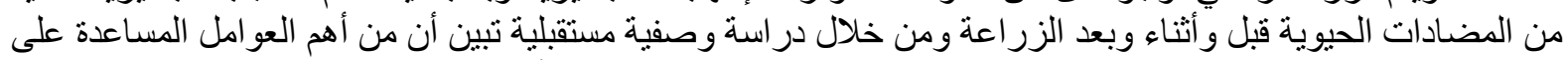

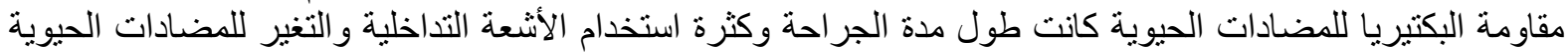
بعد الزر اعة. 
